\title{
MASTIR
}

a -2809

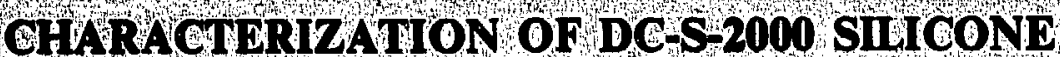 RUDBER AS AN O-RING MATERIAL FOR LASER AMPLIFIER SYSTEMS}

\author{
D. M.Hoffman
}

March 23, 1979

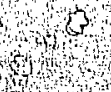

Work performed under the auspices of the U.S Deparment of Energy by the UCLLL under contract number W-7405-ENG 48 . 


\title{
近 \\ LAWRENCE LVERMOAE LABORATORY \\ University of Caltomia Livermore, Californ'a/94650
}

UCRL-62688

\section{CHARACTERIZATION OF DC-S-2000 SILICONE RUBBER AS AN O-RING MATERIAL FOR LASER AMPLIFIER SYSTEMS}

\author{
D. M. Hoffman
}

MS. date: March 23, 1979

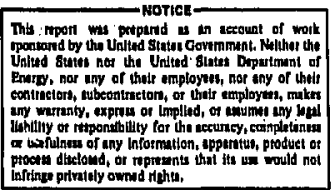




\section{CONTENTS}

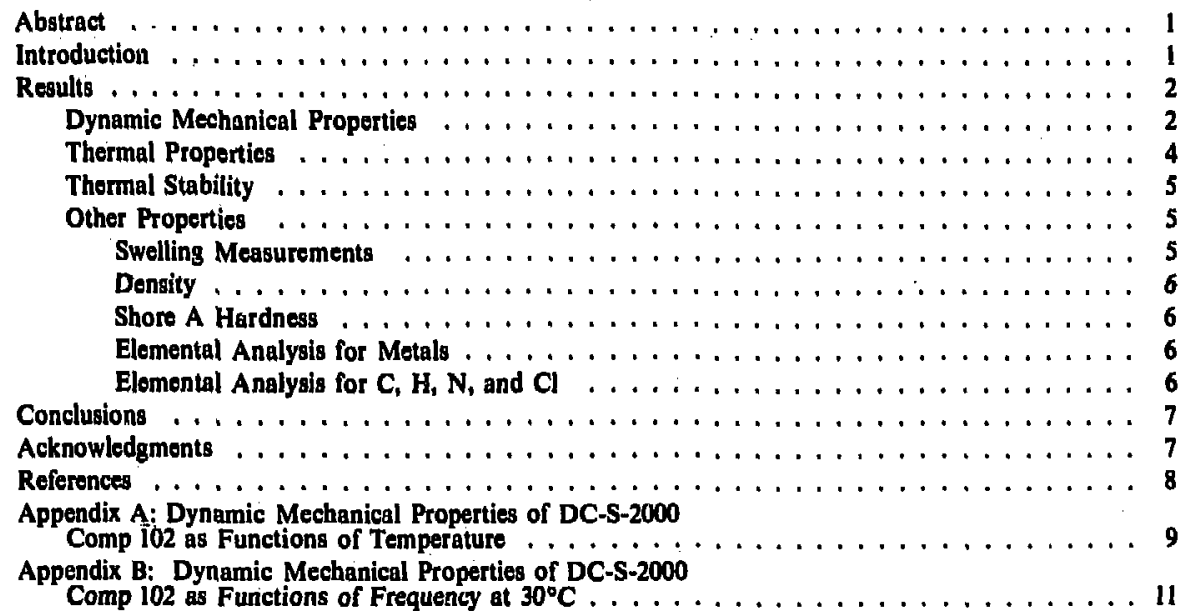




\title{
CHARACTERIZATION OF DC-S-2000 SILICONE RUBBER AS AN O-RING MATERIAL FOR LASER AMPLIFIER SYSTEMS
}

\begin{abstract}
We evaluated mechanical, thermal, thermodynamic, and chemical properties of Dow Corning DC-S-2000, a silicone rubber filled with silica, that was selected as an O-ring material for SHIVA laser amplifiers. We compared the properties of a batch cured in-house with the manufacturer's specifications, and we developed specific quality-control tests to evaluate future production batches of this elastomer. We also examined mechanical and thermal transitions not described in the manufacturer's bulletin. Because the silicone 0 rings must function under prolonged compression, we recommend an examination of the compression properties of DC-S-2000.
\end{abstract}

\section{INTRODUCTION}

Dow Corming Silastic-S-2000 (DC-S-2000), I a silicone rubber filled with silica, was selected as an O-ring material for SHIVA laser amplifiers. This material is sold in an uncured state by the manufac. turer, and the uzer or supplier cures the polymer as needed. We in the Polymeric Materials Group of the Organic Materials Division compared the properties of an experimental batch prepared inhouse with the manufacturer's specifications. We then developed specific quality control tosts to evaluate future production batches of this sillicone rubber To determine potential limitations of DC-S-2000 in the particular application as an O-ring, we also examined mechanical and thermal transitions not listed in the manufacturer's bulletin The major component of DC-S-2000 is a silicone copolymer of dimethyl siloxane and a small amount of methylvinyl siloxane that crosslinks the polymer during the curing process:<smiles>CC(C)[Si](C)(C)O[Si](C)(C)O[Si](C)(C)C</smiles>

As supplied, DC-S-2000 normally contains 2,4dichlorobenzoyl peroxide as a vulcanizing agent. $A$ silica filler is added (about $24 \%$ by weight) to improve mechanical properties such as modulus and tear resistance. 24 .

Table 1 lists the quality control specifications provided by Dow Corning for DC-S-2000 and the average values obtained for production lots. We found that the material we prepared and tested conformed satisfactorily to the manufacturer's specifications. Only a limited quantity of material was available, however, and the tensile strength tests described in the Dow.Corning bulletin were not run. 
TABLE 1. Physical and electrical properties of DCs $2000, \mathrm{a}, \mathrm{b}$

\begin{tabular}{|c|c|c|c|c|c|}
\hline $\begin{array}{c}\text { Property } \\
\text { Pons }\end{array}$ & & $\begin{array}{l}\text { Dow Coming } \\
\text { quality conitrol } \\
\text { specifications? }\end{array}$ & $\begin{array}{r}\text { Averuge values } \\
\text { for production lots } \\
\text { (LLL Comp 102) }\end{array}$ & & Astu \\
\hline 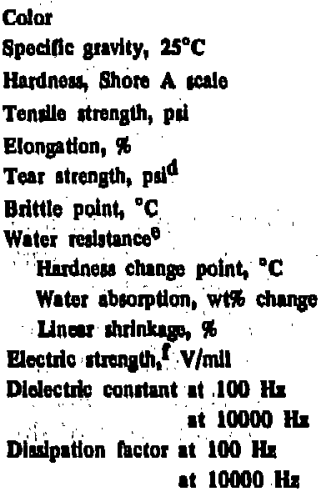 & . & $\begin{array}{l}\text { clear } \\
1.14 \pm 0.02 \\
45-60 \\
750^{\circ} \\
300^{\circ}\end{array}$ & $\begin{array}{l}\text { ctenr } \\
1,13 \text { (1,16) } \\
55(58) \\
1030 \\
530 \\
90 \\
-74 \\
-20 \\
+1.10 \\
3.0 \\
540 \\
2.8 \\
2.8 \\
0.0003 \\
0.0009\end{array}$ & 更 & $\begin{array}{l}\text { D } 676 \\
\text { D } 412 \\
\text { D } 412 \\
\text { D } 624 \\
\text { D } 746 \\
\text { D } 797\end{array}$ \\
\hline
\end{tabular}

"Ref. 1.

broperties measured on specimens cut from alabs (0.075 in. thick) that had been press-molded for $5 \mathrm{~min}$ at $115^{\circ} \mathrm{C}$ and cured for $2 \mathrm{~h}$ at $250^{\circ} \mathrm{C}$.

Mlinimum.

dDie B.

eAfter immerion for $70 \mathrm{~h}$ at $100^{\circ} \mathrm{C}$.

fstandard ASTM electrode $(2 / \mathrm{in})$; voltage increased at $500 \mathrm{~V} / \mathrm{L}$

\section{RESULTS}

Table 2 summarizes the mechanical, thermal, and other properties of Comp 102, the batch of DCS-2000 prepared at LLL. On the basis of the thermal results, we feel that use of DC-S-2000 should be limited to the temperatures between -30 and $150^{\circ} \mathrm{C}$. We did not investigate the aging characteristics and compresslon set behavior of Comp 102 .

\section{DYNAMIC MECHANICAL PROPERTIES}

The dynamic mechanical properties of DC-S2000 were examined from -150 to $50^{\circ} \mathrm{C}$ on the Rheometrics Mechanical Spectrometer (RMS). Figure 1 shows the shear storage $\left(G^{\prime}\right)$ and the shear loss ( $\left.G^{\prime \prime}\right)$ moduli of DC-S-2000 as functions of temperature when the specimens were mechanically stressed at a constant frequency of $10 \mathrm{~Hz}$. The ratio of $\mathbf{G}^{\prime \prime} / \mathbf{G}^{\prime}$, called tan delta, is also plotted on Fig. 1.

At temperatures below the glass transition point $\left(T_{B}=-120^{\circ} \mathrm{C}\right), \quad$ DC-S-2000 is a brittle, semicrystalline solid. The $T_{B}$ temperature corrosponds to the maximum in the $\mathbf{G}^{\prime \prime}$ curve in Fig. I and is much lower than the "brittle point" $\left(-7^{\circ} \mathrm{C}\right)$ given in Table 1. Because the glass transition occurs over a $50^{\circ} \mathrm{C}$-temperature range and depends on the frequency, dynamic mechanical measurements give a much more accurate transition temperature than the ASTM brittle point technique.

At temperatures between $T_{g}$ and the melting point, DC-S-2000 is a flexible semicrystalline solid 
TABLE 2. Physical chancteriatici of DCS2000 Comp 102.

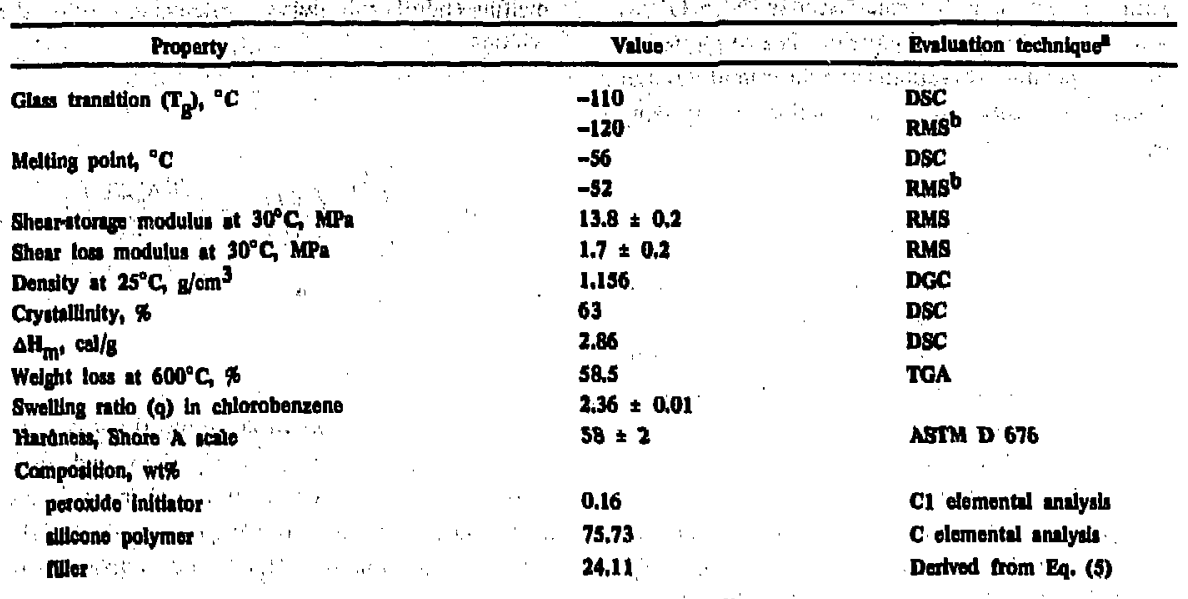

ADEC = Differonthi scanning Cilorimetry; RMS a Rheometrle Mechnilal Spectrometer; DCC = Dandity Gandient Column; TCA = Themogrivinetic Anilydo.

Bransition tompenture determined from the poiltion of the maximum in the loss modulus at $10 \mathrm{~Hz}$.

FIG. 1. Shear storage modulus (G') and the shear loss modulus (G") of DCS-2000 Comp 102 as functions of temperature. When stresaed at a coustunt frequency of $10 \mathrm{~Hz}$, the elastomer on derwent two transitions; the olass transltion at about $-120^{\circ} \mathrm{C}$ and the crystal melting poiat at about $-52^{\circ} \mathrm{C}$.

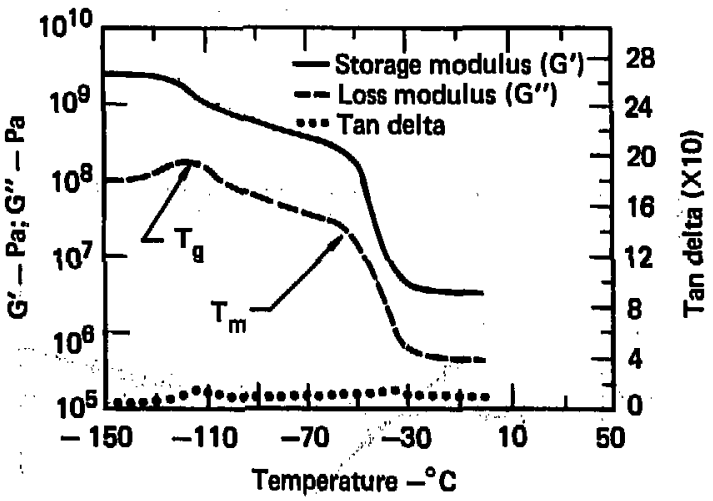

withia shear modulus only olightly less than $10^{9} \mathrm{~Pa}$. The elastomer melti over a fairly broad range $(-50$ to $-30^{\circ} \mathrm{C}$ ) as indicated by tho dramatic decrease of

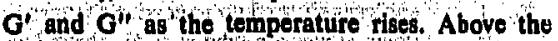
molting point, DC-S-2000 behaves like a vulcanized rubbor with a temperature-dependent storage modulus between $5 \times 10^{6}$ and $2 \times 10^{6} \mathrm{~Pa}$ between $-30^{\circ} \mathrm{C}$ and room temperature $\mathrm{A}$ ppendix $A$ lists the shear storage modulus, loss modulus, and tan delta values from Fig 1 as functions of temperature.

Figure 2 shows the dynamic shear'modulus as a function of frequency at $30^{\circ} \mathrm{C}$. At this temperature, neither the shear storage modulus nor the loss modulus varies significantly over three decades of frequency, indicating that under ambient operating conditions, DC-S-2000 should be stable to 
mechanical vibrations encountered in the laser amplifier system. The dynamic viscosity $\left(N^{\prime}=G^{\prime \prime} / \omega\right.$ where $\omega$ is the angular frequency) is also plotted in Fig. 2. Appendix B tabulates the shear modulus and dynamic viscosity values as functions of stressing, frequency at $30^{\circ} \mathrm{C}$.

\section{THERMAL PROPERTIES}

Figure 3 illustrates a representative differential scanning calorimeter (DSC) curve of Comp 102 that shows the thermal transitions of the polymer. In this type of thermal measurement, the glass transition point is indicated by a discontinuity in the heat capacity; for Comp 102, it occurred at about $-110^{\circ} \mathrm{C}$. The melting temperature $\left(\mathrm{T}_{\mathrm{m}}\right)$ is defined as the intersection of the slope of the melting endotherm with the isothermal baseline. In Fig. $3, T_{m}$ is $-56^{\circ} \mathrm{C}$. The heat of melting $\left(\Delta \mathrm{H}_{m}\right.$, in cal/s of elastomer) is proportional to the area under the melting-endotherm curve, calculated from the relation

$$
\Delta H_{m}=\int_{T_{1}}^{T_{r}}\left(\frac{d Q}{d T}\right) d T=\frac{K A_{p} \Delta T_{B} T_{B}}{W_{p} g^{\prime}},
$$

where $\mathrm{K}$ is the instrument constant $\left(0.144 \mathrm{cal} /{ }^{\circ} \mathrm{C}\right.$ $\min ), \Delta T_{8}$ and $T_{8}$ are, respectively, the $x$ - and $y$-axis sensitivities of the instrument in $: \mathrm{C} / \mathrm{in}$, $\mathrm{a}$ is the heating rate in ${ }^{\circ} \mathrm{C} / \mathrm{min}$, and $W_{p}$ is the weight of the polymer. The value of $\Delta \mathrm{H}_{\mathrm{m}}$ for DC-S-2000 is $\mathbf{2 . 8 6}$ cal/g.

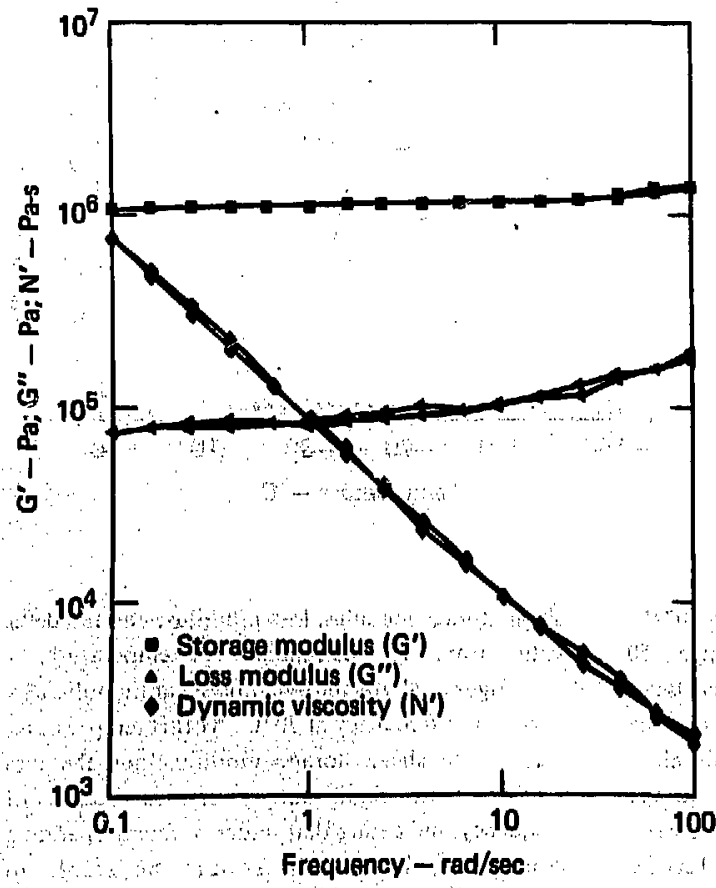

FIG. 2. Dyaamic mechanical properties of DC-S-2000 Comp 102 at 30 $\mathrm{C}$ as functions of stressing frequency. These analyses showed no excessive changes in shaar storage modulus (G'), thear loss

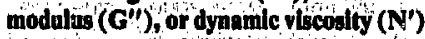
when the sample was subjected to mechahical vibration at nórmal operating temperatires. 


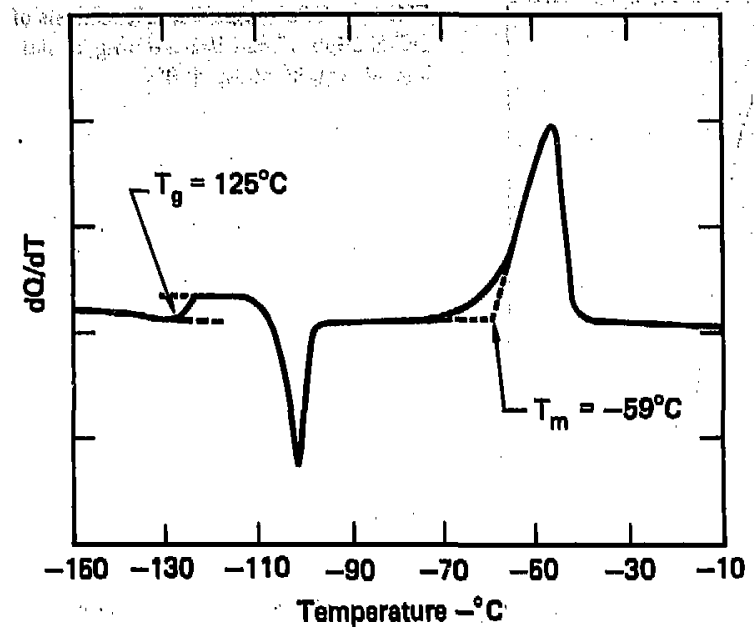

FIG. 3. Typleal difierential seanning calorlmeter (DSC) curve of DC-S-2000 Comp 102 sillcone rubber. This trace shows the glass transition temperature $\left(T_{8}\right)$ as a discontinulty in the hent capacity at $-125^{\circ} \mathrm{C}$. As the temperature rose, the $T_{g}$ was followed by a crystallzatlon exotherm at ahout $-103^{\circ} \mathrm{C}$ and a broad melting endotherm of approximately $2,86 \mathrm{cal} / \mathrm{g}$ between about -60 to $-40^{\circ} \mathrm{C}$.
The percent crystallinity $\left(X_{c}\right)$ of the sample below the melting point is

$$
\mathbf{X}_{\mathrm{c}}=\Delta \mathrm{H}_{\mathrm{m}} / \Delta \mathrm{H}_{\mathrm{f}}
$$

where $\Delta H_{f}$ is the heat of fusion (in cal/g) of a perfectly crystalline polymer of dimethyl siloxane (4.57 cal/g). ${ }^{5}$ Using Eq. (2), we calculated that DC-S2000 Comp 102 is about $63 \%$ crystalline.

\section{THERMAL STABILITY}

We used thermogravimetric analysis (TGA) to testimate the thermal stability of DC-S 2000, At a heating rate of $10^{\circ} \mathrm{C} / \mathrm{min}$, the elastomer began to volatilize very slowly at about $190^{\circ} \mathrm{C}$ (Fig, 4) An unidentified additive, constituting approximately 8 wt\% of the elastomer, volatilized botween 350 and $400^{\circ} \mathrm{C}$. This material was probably a sillcone of low molecular wejght pregent as a golvent for the in thator or used to wet the filler.

Above $450^{\circ} \mathrm{C}$ most of the polymer degraded

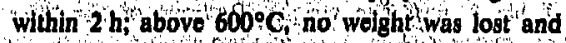
41.5 wt to of nonvolatile residue remained. Wécould not estimate the filleficontent using this technique because the nonvolatile residue contained both silica filler and polymer degradation products. On the basis of this analysis, we recommend that DC-S2000 not be used above $150^{\circ} \mathrm{C}$.

\section{OTHER PROPERTIES}

\section{Swelling Measurements}

The quantity of solvent absorbed by a crosslinked polymer is constant for given solvent in a polymer of constant crosslink density. The swelling ratio $q=V_{g} / V_{j}$ reflects the extent of vulcanization of the polymer. Because DC-S;2000 contains silica as a filler, tho initial volume $V_{0} d e-$ pends on the filler content The degree of crosslinking end the filler content are interdeperident, and the swelling ratio therefore cannot be used to monitor changes in the degree of crosslinking unless the filler concentration is known. Because the filler content can be estimated from elemental analysis, the swelling ratio can be used to indicate variations in crosstink density: For Comp 102, the swelling ratio was 2.36 . 


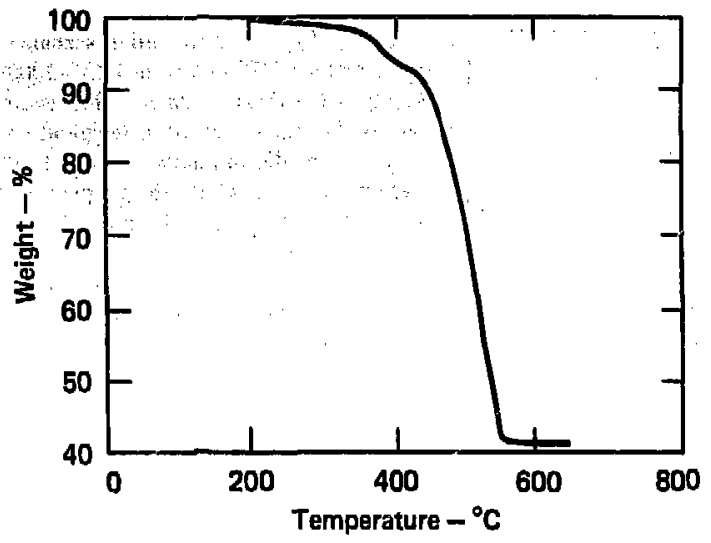

FIG. 4. Thermogravimetric analysis of DC-5-2000 Comp 102 showing a slow loss of weight above $190^{\circ} \mathrm{C}$.

\section{Density}

Density measurements made using the density gradient column (DGC) technique at $30^{\circ} \mathrm{C}$ gave an average value of $1.156 \mathrm{~g} / \mathrm{cm}^{3}$ for Comp $102 \mathrm{sam}$ ples. This density was within the specific-gravity limits indicated by the manufacturer $(1.14 \pm 0.2$ $\mathrm{g} / \mathrm{cm}^{3}$ ).

\section{Shore A Hardness}

Shore A hardness of Comp 102, measured using the ASTM test D 676, was $58 \pm 2$. This value was somewhat higher than the average (55) measured by the manufacturer for production lots (Table 1), but it falls below the upper limit (60) listed in the specifications.

\section{Elemental Analysis for Metols}

We used flame ionizgtion spectrometry to identify trace motals in Comp 102 and found measurable amounts of magnesium, calcium, boron; copper, and aluminum (Table 3). These were probably impurities, contained in the filler rather than metallic catalysts added by the manufacturer. Table 3 lists all dements for which the elastomer was analyzed and the quantities found; for those elements not detected, the limits of the tests are given.

\section{Dre at Anlyos for $\mathrm{C}, \mathrm{H}, \mathrm{N}$, and $\mathrm{C}$}

Because the crosslinking initiator 2,4dichlorobenzoyl peroxide is the only chlorine- containing species in DC-S-2000, an estimate of the weight fraction of peroxide initiator $\left(W_{i}\right)$ can be obtained from the weight fraction of chlorine $\left(W_{C l}\right)$ in the elastomer. The relationship is

$$
W_{i}=2.674 W_{C I}
$$

If no carbon is present in the filler, then the weight fraction of polysiloxane in the elastomer $\left(W_{p}\right)$ is approximately

$$
\mathrm{W}_{\mathrm{p}}=3.086 \mathrm{~W}_{\mathrm{C}}-3.648 \mathrm{~W}_{\mathrm{Cl}} \text {, }
$$

where $W_{C}$ is the weight fraction of all carbon in the elastomer. It is sssumed in Eq. (4) that the carbon in the polymer comes solely from dimethyl siloxane rather than from the methylvinyl siloxane copolymer; we assumed the error introduced by this simplification is small because the methylvinyl siloxane copolymer is only a minor component. The weight fraction of filler $\left(W_{f}\right)$ in the elastomer is then

$$
\begin{aligned}
w_{c} & =1-w_{1}-w_{p} \\
& =1-3.086 W_{c}+0.974 w_{c 1}
\end{aligned}
$$

Table 2 gives the weight fractions of the three Comp 102 components; Table 3 lists the results of the $\mathrm{C}, \mathrm{H}, \mathrm{N}$, and $\mathrm{Cl}$ analyses. 
TABLE 3. Chemical analysits of DCS-2000 Comp 102.

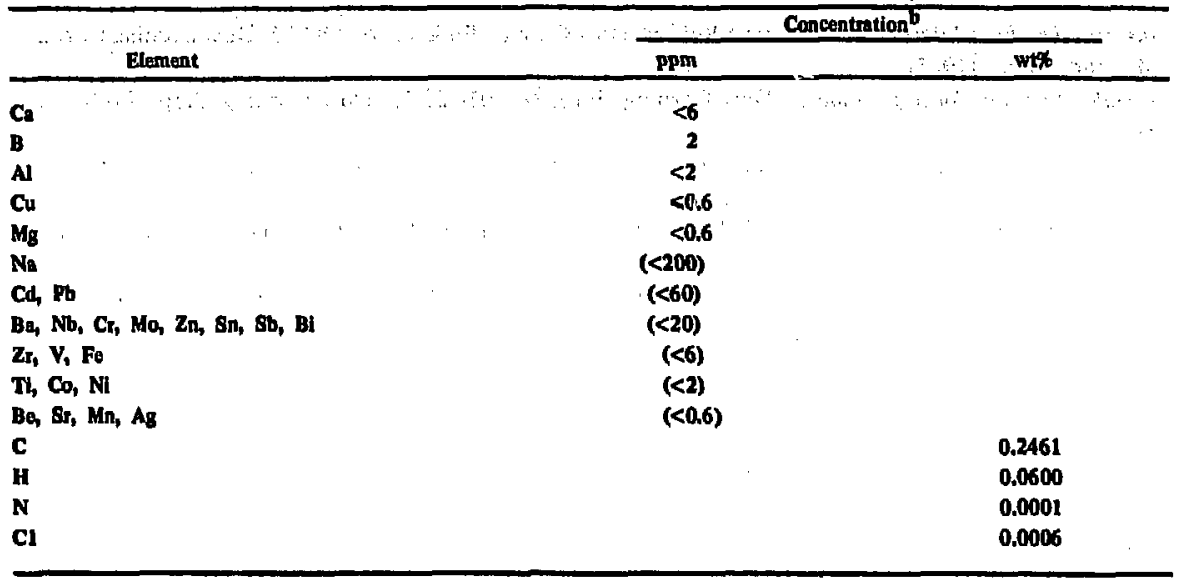

Dotermined by tame lonization opectrometry.

bValues in parentheass givo the detection timits for elements that were not found.

\section{CONCLUSIONS}

Simple tests such as Shore A hardness (ASTM D 676), tensile strength (ASTM D 412), and solvent swelling tests should be sufficient to verify the quality of production lots of DC-S-2000 silicone rubber and to identify undesired changes in mulation. Elastomer batches that do not meet the manufacturer's specifications should be rejected as unsuitable O-ring material, and drastic deviation of test results from the test limits should prompt a more detailed analysis of the batch.

Because only a limited quantity of Comp 102 was available, we could not measure the tensile strength, but we believe that this test should be conducted on future samples of DC-S-2000. We also feel that, because the silicone $\mathbf{O}$-rings must function under prolonged compression, the results of a compression set test (ASTM D 395) of DC-S-2000 would be of interest. On the basis of the observed thermal stability of this material, however, we suggest that compression-test temperatures should not exceed $85^{\circ} \mathrm{C}$

We recommend that the Laser Group run the Shore A hardness, solvent swelling, and tensile strength tests on future lots of DC-S-2000 to maintain quality control standards. Special problems with DC-S-2000 should be referred to the Polymeric Group of the Organic Materials Division for analysis and proposed solutions.

\section{ACKNOWLEDGMENTS}

We thank Leonard Caley for his assistance with the dynamic mechanical measurements, Barbara McKinley and Patricia Crawford for the thermal measurements, LeRoy Althouse and Albert Buckner for the hardness measurements, and Ing
Chiu for the density measurements. We gratefully acknowledge the support of the Lawrence Livermore Laboratory chemistry facility for providing elemental analyses. 
REFERENCES

1. Information about Silastic Brand Silicone Rubber, Dow Corning Bulletin No. 09-045, Dow Corning Corp,, Midland, Mich. (1963).

2. A Guide to Dow Corning Products, Dow Corning Form No. 02-320-77, Dow Corning Corp., Midland, Mich. (1977).

3. Engineering with Silastic Silicone Rubbers, Dow Corning Form No. 09-132, Dow Corning Corp., Midland, Mich. (1965).

4. Compounding with silastic Gums and Bases, Dow Corning Form No. 09-257, Dow Corning Corp., Midland, Mich. (1968).

5. C. L. Lee, O. K. Johannson, O. L. Flanigan, and P, Hahn, Poly. Propr., Amer, Chem. Soc., Div, Poly. Chem. 10, 1311 (1969).

Kug/lo

8 


\section{APPENDLX A \\ DYNAMIC MECHANICAL PROPERTIES OF DC-S-2000 COMP 102 AS FUNCTIONS OF TEMPERATURE}

Shear storage modulus ( $\left.G^{\prime}\right)$ and shear loss modulus (G") of DC-S-2000 Comp 102 as functions of temperature while subjected to mechanical vibration $(10 \mathrm{~Hz})$.

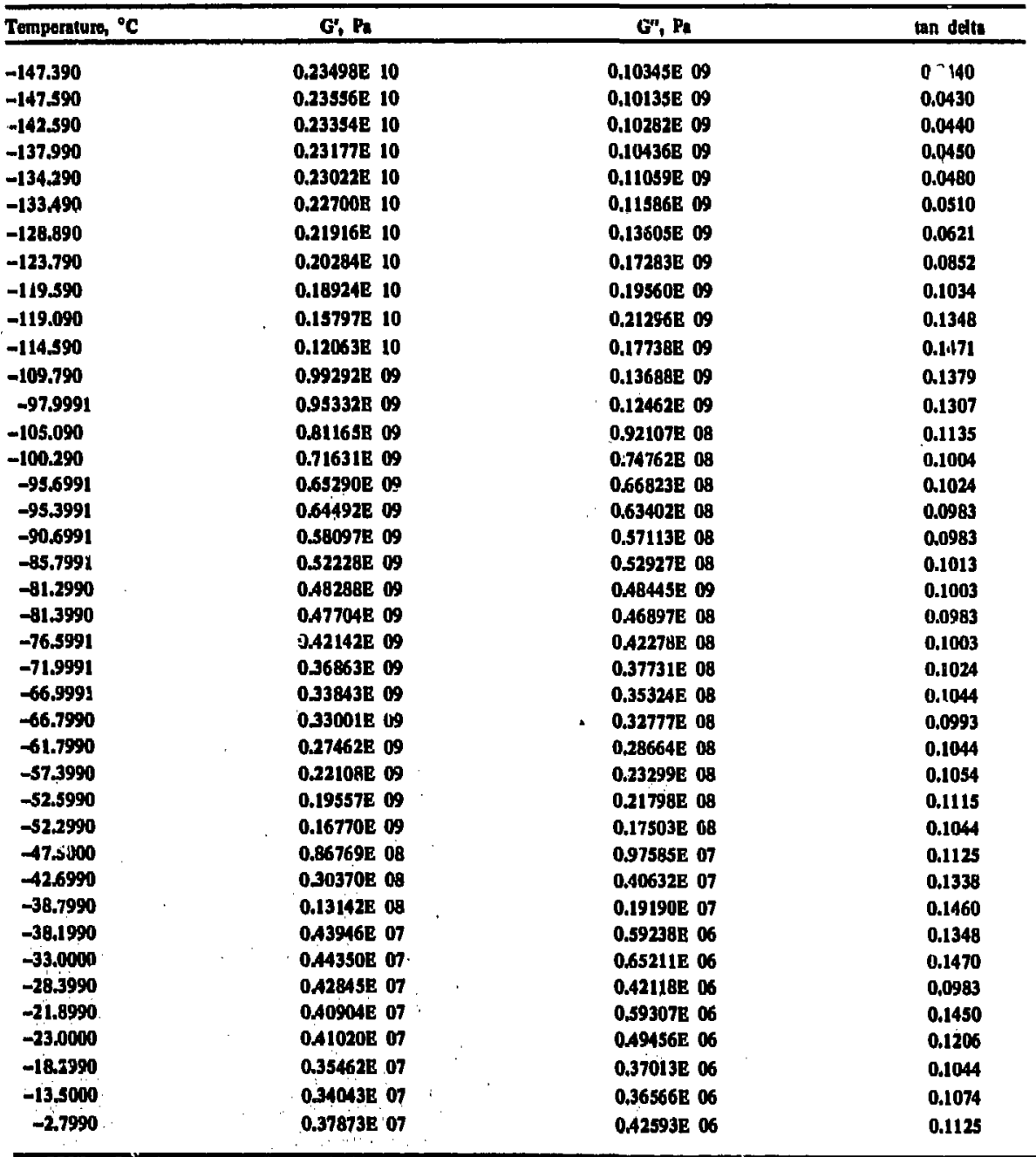




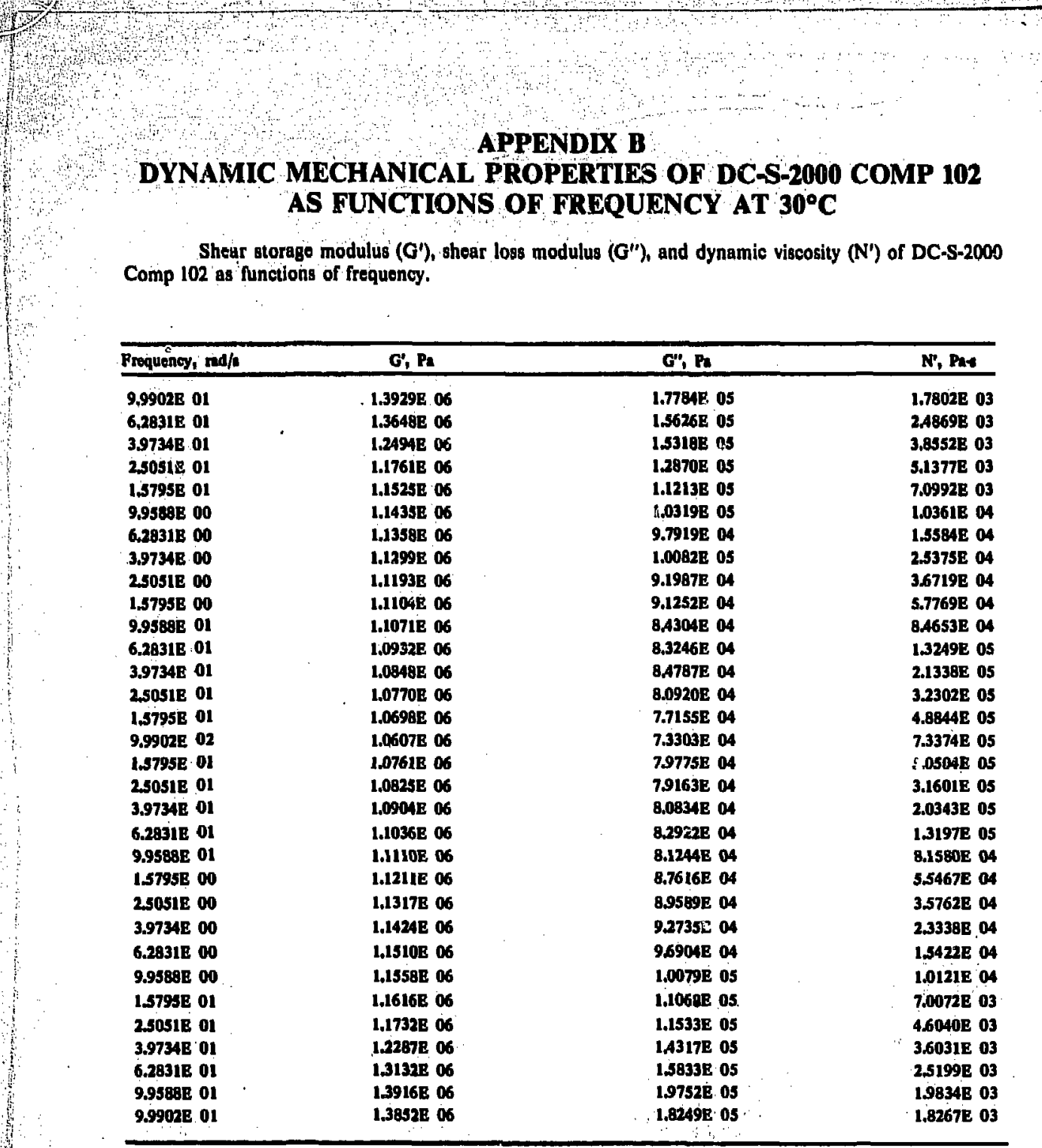

